\title{
Fabrication of silicon based glass fibres for optical communication
}

\author{
VIVEK P KUDE ${ }^{\dagger}$ and R S KHAIRNAR* \\ School of Physical Sciences, SRTMU, Vishnupuri, Nanded 431 606, India \\ ${ }^{\dagger}$ Department of Applied Physics, M.G.M. College of Engineering, Nanded 431 606, India
}

MS received 15 September 2003; revised 5 December 2003

\begin{abstract}
Silicon based glass fibres are fabricated by conventional fibre drawing process. First, preform fabrication is carried out by means of conventional MCVD technique by using various dopants such as $\mathrm{SiCl}_{4}$, $\mathrm{GeCl}_{4}, \mathrm{POCl}_{3}$, and $\mathrm{FeCl}_{3}$. The chemicals are used in such a way that step index single mode fibre can be drawn. The fibre drawing process consists of various steps such as heating the preform at elevated temperature, diameter monitor, primary and secondary coating, and ultra violet radiation curing. The fibres are then characterized for their geometrical and optical properties. The drawn fibre has diameter of core and cladding to be $8 \cdot 3 \mu \mathrm{m}$ and $124 \cdot 31 \mu \mathrm{m}$, respectively whereas non-circularity is found to be $4 \cdot 17 \%$ for core and $0 \cdot 26 \%$ for cladding as seen from phase plot. Mode field diameter is found to be $8.9 \mu \mathrm{m}$ and $9.2 \mu \mathrm{m}$ using Peterman II and Gaussian method, respectively. The fabricated fibres showed the signal attenuation of $0 \cdot 35 \mathrm{~dB} / \mathrm{km}$ and $0 \cdot 20 \mathrm{~dB} / \mathrm{km}$ for $1310 \mathrm{~nm}$ and $1550 \mathrm{~nm}$, respectively as measured by the optical time domain reflectometer (OTDR).
\end{abstract}

Keywords. Optical fibre; preform fabrication; fibre drawing; mode field diameter; OTDR measurements.

\section{Introduction}

Numerous techniques (Beals et al 1979; Izawa et al 1979; MacChesney 1980) are developed for fabrication of glass fibres so as to get better optical properties suitable for optical communication, and also to combat with ever increasing demand of fibre in diverse application areas. Various processes are being modified such as preform making, melting process, melting environment, homogenization/fining, and reactive atmosphere processing (France Paul et al 1990). Hermetic carbon coating has been shown to be effective barrier for water and hydrogen (Lamair et al 1988; Huff et al 1989; Lu et al 1989). Polymers such as ultra violet radiation curable acrylate and Teflon-FEP are used as coating for fluoride glass optical fibres (Ihishi et al 1990). However, these materials have high permeability of water and hence are not adequate for fabrication of high strength optical fibres. Oxide glass has low permeability of water than fluoride/polymer fibres and hence has high durability as compared to fluoride glass. Efforts are also made to fabricate plastic optical fibres as a compliment for glass fibres in short distance communication links (Izawa et al 1977). The fabrication and characterization of side hole single mode optical fibres have been studied (Izawa and Sudo 1987). The thermal modeling is reported for optical fibres drawing process to see the effects of fibre diameter and drawing speed on

\footnotetext{
*Author for correspondence
}

temperature distribution (Papamichael and Miaoulis 1990). The most fundamental physical parameter for optical fibre is geometry, since the dimension of the fibre determines its ability to splice and to be terminated. Therefore, when the fibre is fabricated, it is important to study the abovementioned parameters, which are useful in assessing the communication performance of the fibre. In the present paper, we report the fabrication of single mode step index silica glass fibre and its geometrical characterization. For this, fabrication of preform is initially carried out. Later on, preform is mounted on the fibre-drawing machine (Nextrom make). The drawn fibres are then characterized for their geometrical shapes by means of geometrical analyser instrument from GN Nettest (model 2400 unit), USA. The mode field diameter (MFD) is measured with the wide angle variable aperture unit (WAVAU, Model 2200) of GN Nettest, USA. Finally the signal attenuation is measured by back scattering technique using OTDR setup. All the experimental work is carried out at Sterlite Optical Technology Ltd., Aurangabad.

\section{Experimental}

\subsection{Preform fabrication}

The preform is fabricated by means of modified chemical vapour deposition (MCVD) process. Initially the substrate tube is cleaned by hydrofluoric acid and fire-polished to remove stresses in the glass and later on etched with 
freon to remove surface impurities. The reactants $\left(\mathrm{SiCl}_{4}+\right.$ $\mathrm{O}_{2}$ ) are introduced at one end of the rotating tube while an exhaust is located at the other end. Cladding layer is made by deposition of materials such as $\mathrm{SiCl}_{4}, \mathrm{GeCl}_{4}$ and $\mathrm{POCl}_{3}$ in different environments such as oxygen, helium and freon. During clad process, freon reduces the refractive index of clad and reaction converts halides into oxides. Approximately, 25-30 layers of cladding are deposited on the inside of the substrate tube. A core layer is deposited by means of compounds like $\mathrm{SiCl}_{4}, \mathrm{GeCl}_{4}$ in gaseous environment of oxygen, helium and freon. $\mathrm{GeCl}_{4}$ converts to $\mathrm{GeO}_{2}$, which serves as a dopant to increase the refractive index of the core layer, whereas helium lowers the deposition temperature (Fleming 1978). The flow of reactants and the speed of traversing oxyhydrogen burner are closely monitored using a video camera. When the desired thickness is achieved, valve is closed to stop the flow of the reactants. After deposition of core layers on the inner side of tube, this composite tube is heated to high temperature from outside so that it collapses to form a solid rod. The freon gas is passed while collapsing so that the core has higher refractive index than the clad as well as the solid glass rod becomes free of air bubbles. The chlorine gas is also used in combination with freon so as to remove $\mathrm{OH}$ from $\mathrm{SiO}_{2}$. This preform is subjected to fibre drawing process.

The reactions that take place during preform fabrication are as follows.

$$
\begin{gathered}
\mathrm{SiCl}_{4}+\mathrm{SO}_{2} \rightarrow \mathrm{SiO}_{2}+2 \mathrm{Cl}_{2}: \text { Conversion to quartz } \\
\mathrm{GeCl}_{4}+\mathrm{O}_{2} \rightarrow \mathrm{GeO}_{2}+2 \mathrm{Cl}_{2}: \text { Alteration of refraction } \\
4 \mathrm{POCl}_{4}+3 \mathrm{O}_{2} \rightarrow 2 \mathrm{P}_{2} \mathrm{O}_{5}+6 \mathrm{Cl}_{2}: \text { Alteration of } \\
\text { refractive index }
\end{gathered}
$$

Freon $\left(\mathrm{CCl}_{4} \mathrm{~F}_{2}\right)$ on heating forms the compound, $\mathrm{SiF}_{4}$, instead of $\mathrm{SiO}_{2}$, which lowers the deposition rate of $\mathrm{SiO}_{2}$. Figure 1 shows the fabricated preform. The preform has diameter typically in the range of $25-60 \mathrm{~mm}$ and 600 $800 \mathrm{~mm}$ in length, respectively.

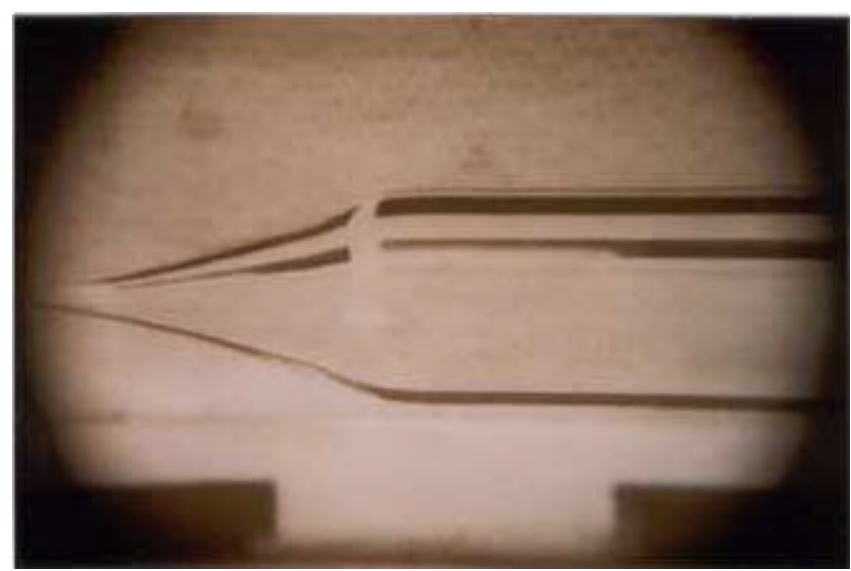

Figure 1. The photograph of preform.

\subsection{Fibre drawing}

The performance of optical fibres, specifically the transmission losses, bandwidth and strength, is strongly influenced by the fibre drawing and coating process. This process must be treated as an integrated operation designed to impart desired properties to the resulting fibre. The essential components of whole process are shown in the form of flow chart in figure 2, which consists of feed glass, heat source, fibre diameter monitor, cooling system, coating applicator, curing apparatus, and fibre puller/winding mechanism. The components are arranged in vertical position to take advantage of gravitational forces. The feed glass preform is fed at speed of $0.02-0.03 \mathrm{~cm} / \mathrm{s}$ depending on the heat source, preform diameter and draw speed. Continuous lengths of more than $40 \mathrm{~km}$ have been drawn from such a preform in one drawing. Fibre drawing proceeds by heating the tip of the preform to a molten state and allowing it to extend under the force of gravity downward into a fine-diameter filament without the use

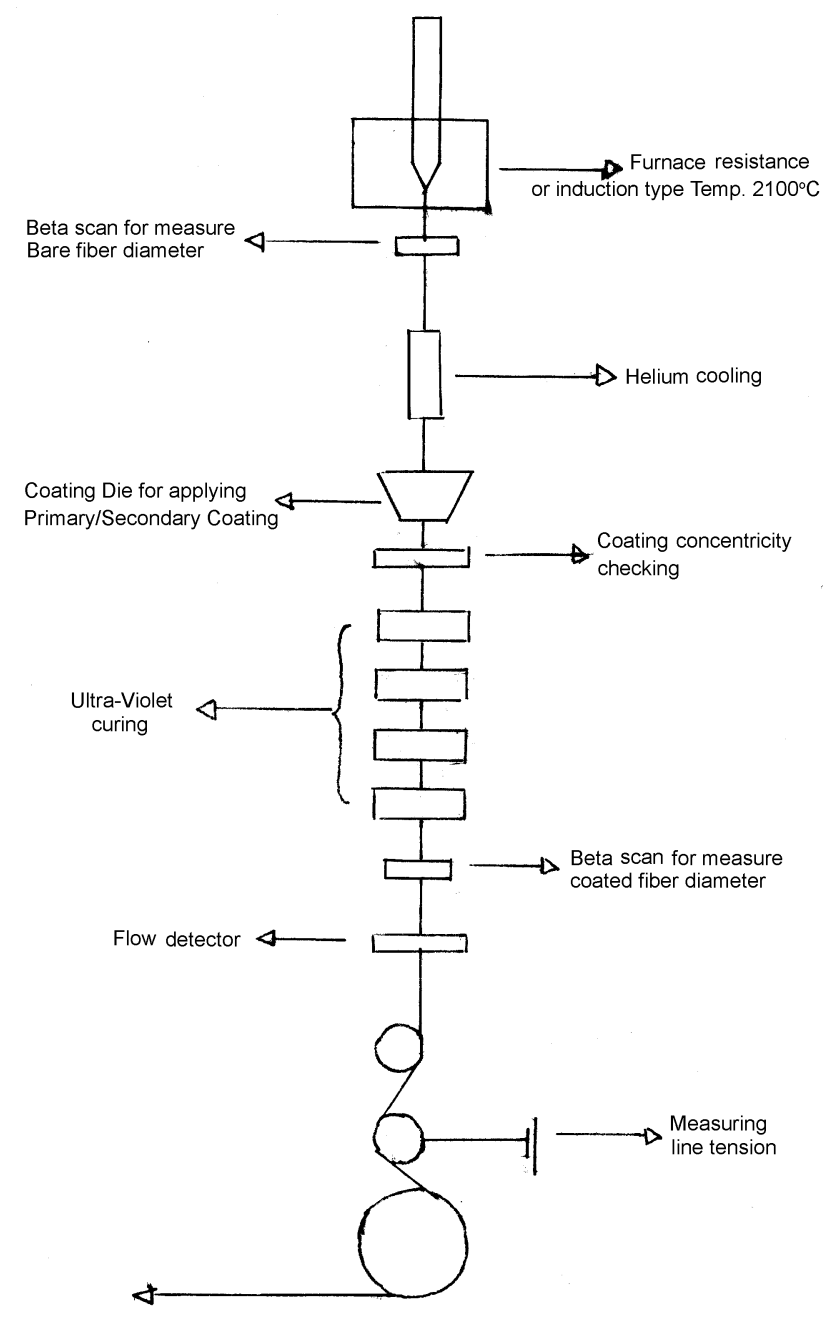

Figure 2. Flow chart of fibre drawing and coating process. 
of any die mechanism whereas pulling and winding mechanism sustains a drawing force. The fibre diameter is monitored continuously as the fibre passes through the furnace. Any variation of the fibre diameter is detected by a control device that automatically readjusts the temperature and the speed of pulling mechanism to compensate for initial change. Since this bare fibre consists of core and clad, the fibre diameter is an important parameter, which influences wave propagation phenomenon used in optical fibre. When the fibre comes out of the furnace, it is cooled in the presence of helium gas without altering its physical dimension. Then it enters the coating applicator immediately. A clean environment is maintained at this junction to reduce the risk of contaminating the fibre surface. Polymer coating is applied concentrically in sufficient thickness and solidified using ultra-violet curing technique very rapidly. Later on, it is scanned for the detection of defects such as voids, lumps and uncoated section.

\section{Characterization}

\subsection{Fibre core and clad measurement}

Core clad diameter is measured by means of geometry analyser wide angle variable aperture unit (WAVAU) from GN Nettest (Model 2400), USA. Light is launched from one end of fibre having $1310 \mathrm{~nm}$ wavelength by means of core illuminator. The light comes out at other end of the fibre which is also illuminated to see core cladding edges distinctly. This core cladding picture is transferred on computer for digitizing. Least square technique is used for ellipse fitting to this digitized image.

The data is given as $\left(X_{\mathrm{i}}, Y_{\mathrm{i}}\right)$ and the modeled ellipses centre as $\left(X_{\mathrm{o}}, Y_{\mathrm{o}}\right)$ with polar angle, $\theta$, and major and minor axial radii, $A$ and $B$, respectively. The calculations of the best fit ellipse finds the minimum error $(\mathrm{Se})$ using following formula

$$
\begin{aligned}
S e^{2}= & \sum\left\{\left[\left(X_{\mathrm{i}} \cos \theta+Y_{\mathrm{i}} \sin \theta-X_{\mathrm{o}}\right)^{2} / A^{2}\right]+\right. \\
& {\left.\left[\left(Y_{\mathrm{i}} \cos \theta-X_{\mathrm{i}} \sin \theta-Y_{\mathrm{o}}\right)^{2} / B^{2}\right]\right\}^{2} . }
\end{aligned}
$$

The measured result of diameter can be obtained from the geometric mean of major and minor axial radii

$$
\text { Diameter }=2 \sqrt{ }\left[\left(A^{2}+B^{2}\right) / 2\right] \text {. }
$$

The non-circularity measured in terms of percentage is given by

$$
\text { Non-circularity }=\{[(A-B) / \text { diameter }] 200\} \% \text {. }
$$

Typical phase plots in figures 3 and 4 show the modeled data (line) and actual measured data (dots) as a function of $\theta$ for cladding and core of the fibre. Table 1 lists the diameters and noncircularity for core and cladding. It is seen that clad ovality is maintained constant within $1 \%$ and core ovality within $6 \%$.

\subsection{Mode field diameter}

The mode field diameter is a measure of distribution width of electric field intensity. Small value of mode field diameter for a fibre denotes less bending losses for optical signal. A variable wavelength light source is scanned through its spectral range and enters the fibre input end face through a lens and a mode stripper. The near-field

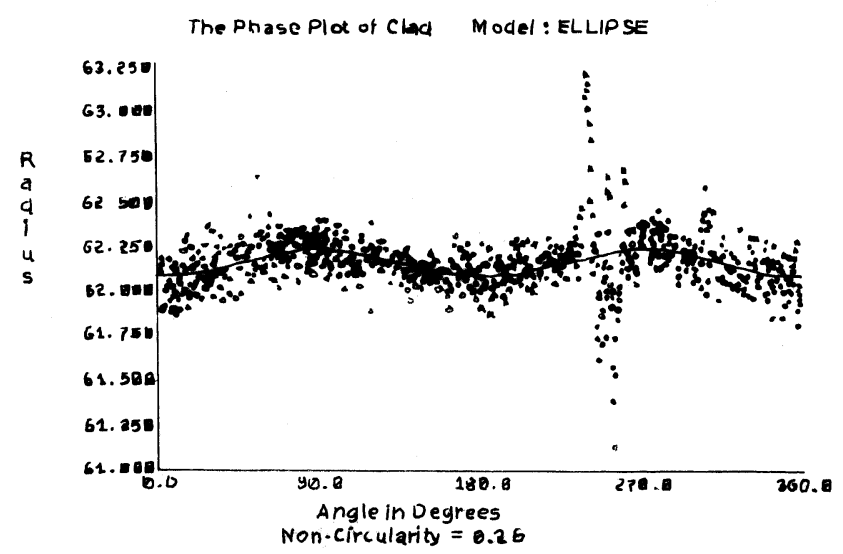

Figure 3. The phase plots for cladding of the fabricated fibre.

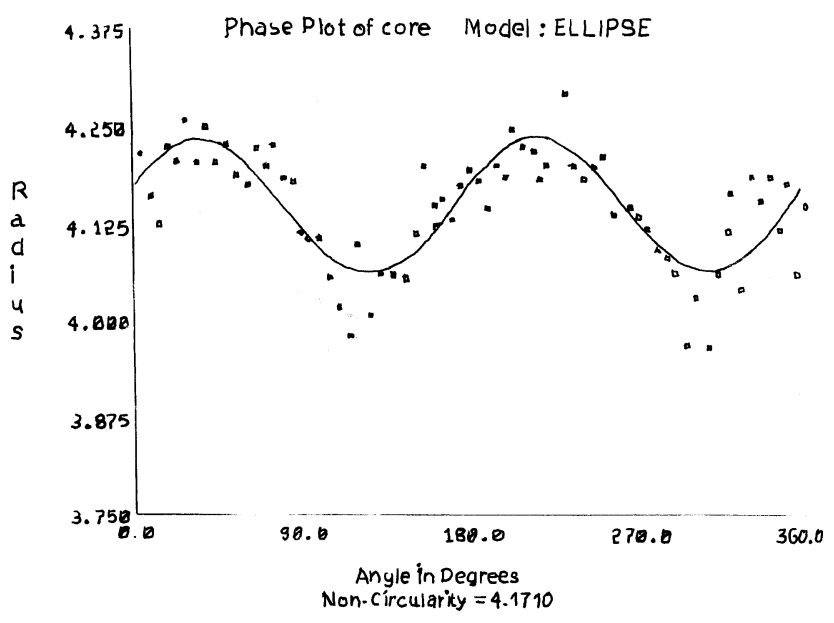

Figure 4. The phase plots for core of the fabricated fibre.

Table 1. Glass fibre geometry measurements.

\begin{tabular}{lcc}
\hline Layer & Diameter $(\mu \mathrm{m})$ & Non-circularity $(\%)$ \\
\hline Core & $8 \cdot 30$ & $4 \cdot 17$ \\
Clad & $124 \cdot 3$ & $0 \cdot 26$ \\
\hline
\end{tabular}


light pattern is observed at the output end of fibre. As wavelength increases from below the cut-off, the diameter of the $L P_{\mathrm{o} 1}$ mode and the $L P_{11}$ mode increases at first. The mode field diameters are computed by two methods, viz. Gaussian and Peterman II techniques, separately (Ghatak and Thyagarajan 1999). The formula given below is used to compute the mode field diameter $(2 \mathrm{Wo})$ by Gaussian method

$$
\begin{aligned}
& E^{2}=\sum\left\{P_{\mathrm{i}}-P_{\mathrm{o}}\left[1-\exp \left(-m \tan ^{2} \theta_{\mathrm{i}}\right)\right]\right\}, \\
& 2 W o=(\lambda / \pi) \sqrt{ }(2 m),
\end{aligned}
$$

where $P_{\mathrm{i}}$ is the measured power through aperture $\mathrm{i}$ and $\theta_{\mathrm{i}}$ the half angle of the cone subtended by aperture $i$, and $\lambda$ is wavelength. Equation (1) minimizes the square, $E^{2}$, by adjusting the parameter, $P_{\mathrm{o}}$ and $m$.

The mode field diameter $(2 \mathrm{Wo})$ according to Peterman II is computed as follows

$$
2 W o=[(\sqrt{2})(\lambda / \pi)]\left[\int_{0}^{\pi / 2} a(\theta) \sin 2 \theta d \theta\right]^{-1 / 2},
$$

where $a(\theta)=1-\left[P(\theta) / P_{\max }\right]$ and $P_{\max }$ the peak-measured power.

Figure 5 shows typical graph of power vs angle $\theta$. The mode field diameter is found to be $8.9 \mu \mathrm{m}$ and $9.2 \mu \mathrm{m}$ using Gaussian and Peterman II technique, respectively.

\subsection{Loss measurement using OTDR}

Optical time domain reflectometer (OTDR) is a primary tool to measure insertion loss as well as manufacturing faults like breaks and bends in the fibre.

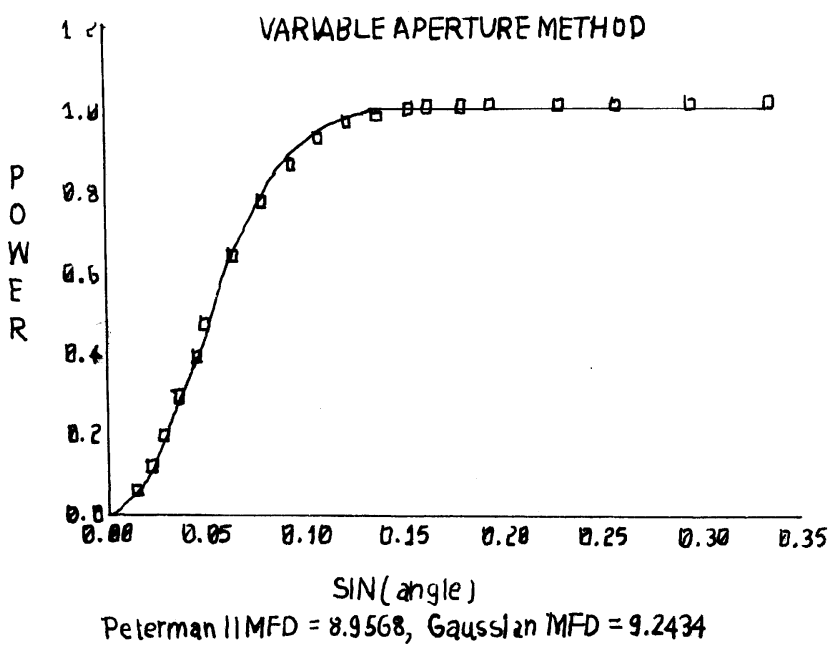

Figure 5. The graph shows variation of power as a function of $\theta$ of the fabricated fibre for computation of mode field diameter at $1310 \mathrm{~nm}$.
OTDR measurements are carried out by means of back scattering technique by using GN Nettest model CMA 4000 instrument. A silica fibre of more than a kilometer in length, having core diameter of $8.3 \mu \mathrm{m}$, is ground polished and connected to the fibre stage of OTDR setup. A

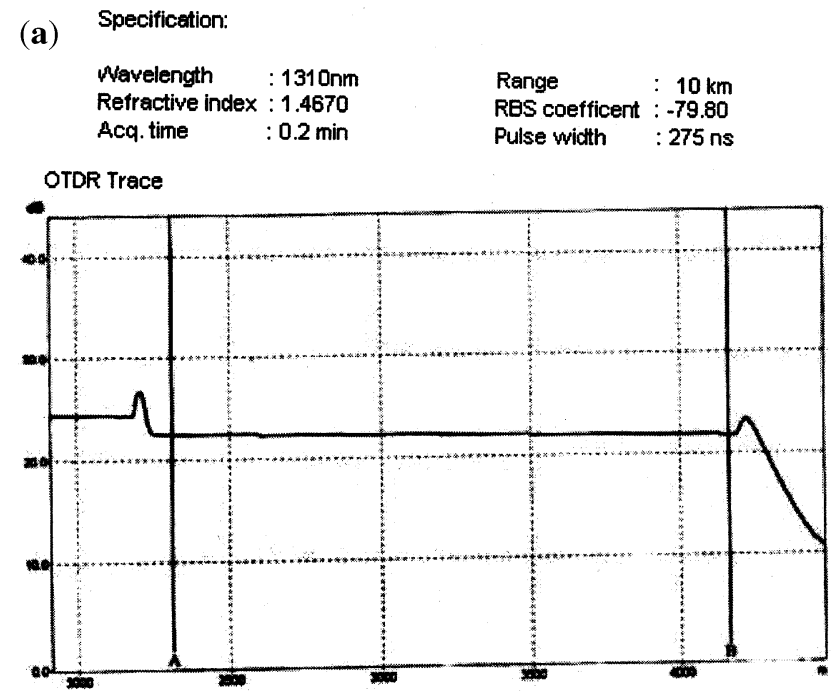

Marker information

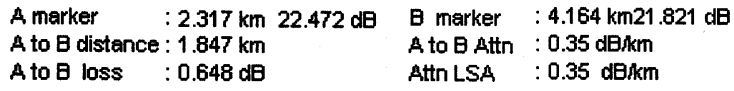

(b) Specification:
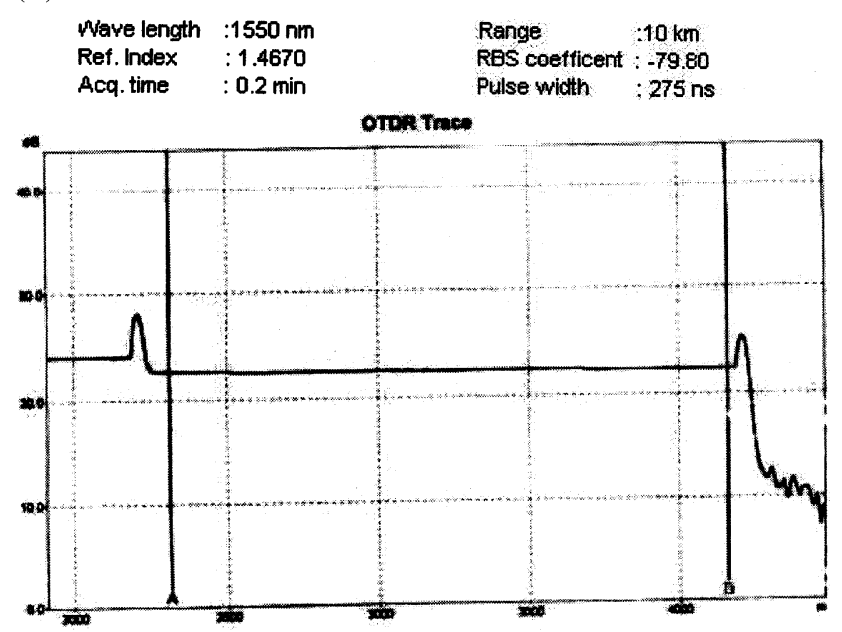

Marker information

$\begin{array}{llll}\text { A marker } & : 2.317 \mathrm{~km} 22.265 & \text { B marker } & : 4.164 \mathrm{~km} 22.288 \\ \text { A to } \mathrm{E} \text { distance }: 1.847 \mathrm{~km} & \text { A to B Atth } & 0.20 \mathrm{~dB} / \mathrm{km} \\ \text { A to } \mathrm{B} \text { loss } & 0.367 \mathrm{~dB} & \text { Attn LSA } & 0.20 \mathrm{~dB} / \mathrm{km}\end{array}$

Figure 6. OTDR signal trace of a synthesized optical fibre. The slope of a trace indicated gradual attenuation over a length of a fibre. The spike at ' $A$ ' shows the power loss of a signal at the connector while the spike at ' $B$ ' marks the end of the fibre. (a) OTDR trace taken at $1310 \mathrm{~nm}$ and (b) OTDR trace taken at $1550 \mathrm{~nm}$ 
square pulse signal of $275 \mathrm{~ns}$ is injected onto the optical fibre. A small amount of the pulse is continuously reflected back in the opposite direction by irregularities in the optical fibre structure. By measuring the amount of backscatter signal vs time, the loss vs distance of the optical fibre is measured. Figures 6(a) and (b) display the OTDR trace for $1310 \mathrm{~nm}$ wavelength and for $1550 \mathrm{~nm}$ wavelength signal, respectively. The vertical scale is the reflected signal level on a logarithmic scale in $\mathrm{dB}$. The horizontal axis corresponds to the distance between the instrument and a location in the fibre under test. Typically, the positive spike near point ' $A$ ' is due to the reflection at the front connector whereas the one beyond point ' $B$ ' is due to fibre end. Both the traces show gradual decrease in the signal along the fibre length, the slope of which gives the signal attenuation in $\mathrm{dB} / \mathrm{km}$. Since there are no positive and negative spikes found between points ' $A$ ' and ' $B$ ' along the OTDR trace, it is confirmed that there are no breaks, cracks and discontinuity within the core material of the fabricated fibre. As seen from the figure, for a fibre length of 1847 meter, the signal loss obtained is $0.648 \mathrm{~dB}$ and $0.367 \mathrm{~dB}$ at $1310 \mathrm{~nm}$ and $1550 \mathrm{~nm}$, respectively. Thus the attenuation is found to be $0.35 \mathrm{~dB} / \mathrm{km}$ and $0.20 \mathrm{~dB} / \mathrm{km}$ for $1310 \mathrm{~nm}$ and $1550 \mathrm{~nm}$, respectively.

\section{Conclusion}

The silica glass fibre is fabricated by conventional technique having core and clad diameter of $8.3 \mu \mathrm{m}$ and $124.3 \mu \mathrm{m}$, respectively, whereas core and clad non-circularity measured is found to be $4.17 \%$ and $0.26 \%$, respectively, which is within the tolerable limit of $6 \%$ and $1 \%$, respectively. The value of mode field diameter is obtained as $8.9 \mu \mathrm{m}$ and $9.2 \mu \mathrm{m}$ by Gaussian and Peterman II technique, respectively at $1310 \mathrm{~nm}$. The OTDR measurement of the fabricated fibre shows the optical loss to be $0.35 \mathrm{~dB} / \mathrm{km}$ and $0.20 \mathrm{~dB} / \mathrm{km}$ for $1310 \mathrm{~nm}$ and $1550 \mathrm{~nm}$ wavelength, respectively. These results indicate that the drawn fibres can be useful for optical signal communication.

\section{Acknowledgements}

The authors are thankful to Prof. (Dr) S A Suryawanshi, SRTM University, Nanded, for constant encouragement. One of the authors (VPK) gratefully acknowledges Sterlite Optical Technology Ltd., Aurangabad, for providing experimental facilities.

\section{References}

Beals K J, Day C R, Duncan W J, Dunn A G, Dunn P L, Newns G R and Wright J V 1979 5th European conference on optical fibre communication (New York: McGraw Hill)

Fleming J W 1978 Electron Lett. 14326

France Paul, Carter S F, Moore W and Williams J R 1990 in Optical fibre material and processing, MRS symp. proc. (Pennsylvania, USA: Materials Research Society) 172134

Ghatak A and Thyagarajan J 1999 Textbook of introduction to fibre optics (New Delhi: Cambridge University Press) p. 435

Huff R G, Dimarcello F V and Hart Jr A C 1989 Tech. Digest, OFC paper TUG2

Ihishi V, Fujiura K and Takahashi S 1990 MRS symp. proc. (Pennsylvania, USA: Materials Research Society)

Izawa T and Sudo S 1987 Optical fibre materials and fabrication (Tokyo: KTK scientific) p. 36

Izawa T, Shabita N and Takeda A 1977 Appl. Phys. Lett. 3133

Izawa T, Sudo S and Hanawa F 1979 Trans. IEEE 62779

Lamair P J, Kranz K S, Walker K L and Huff R G 1988 Elect. Lett. 24132

Lu K E, Lee M T, Powers D R and Glassman S 1989 in Tech. Digest, PDI, OFC 425

MacChesney J B 1980 Proc. IEEE 681181

Papamichael H and Miaoulis J 1990 MRS symp. proc. (Pennsylvania, USA: Materials Research Society) 172 p. 43 